\title{
Reaction Rate Benchmark Experiments with Miniature Fission Chambers at the Slovenian TRIGA Mark II Reactor
}

\author{
Žiga Štancar, Tanja Kaiba \\ and Luka Snoj \\ Reactor Physics Department \\ Jožef Stefan Institute \\ Jamova cesta 19, SI-1000 Ljubljana \\ e-mail: ziga.stancar@ijs.si
}

\author{
Loïc Barbot, Christophe Destouches, \\ Damien Fourmentel and Jean-François Villard \\ $C E A, D E N, D E R$, \\ Instrumentation, Sensors and Dosimetry Laboratory \\ Cadarache, F-13108 St-Paul-Lez-Durance \\ e-mail:loic.barbot@cea.fr
}

\begin{abstract}
A series of fission rate profile measurements with miniature fission chambers, developed by the Commisariat à l'énergie atomique et aux énergies alternatives, were performed at the Jožef Stefan Institute's TRIGA research reactor. Two types of fission chambers with different fissionable coating $\left({ }^{235} \mathrm{U}\right.$ and $\left.{ }^{238} \mathrm{U}\right)$ were used to perform axial fission rate profile measurements at various radial positions and several control rod configurations. The experimental campaign was supported by an extensive set of computations, based on a validated Monte Carlo computational model of the TRIGA reactor. The computing effort included neutron transport calculations to support the planning and design of the experiments as well as calculations to aid the evaluation of experimental and computational uncertainties and major biases. The evaluation of uncertainties was performed by employing various types of sensitivity analyses such as experimental parameter perturbation and core reaction rate gradient calculations. It has been found that the experimental uncertainty of the measurements is sufficiently low, i.e. the total relative fission rate uncertainty being approximately $5 \%$, in order for the experiments to serve as benchmark experiments for validation of fission rate profiles. The effect of the neutron flux redistribution due to the control rod movement was studied by performing measurements and calculations of fission rates and fission chamber responses in different axial and radial positions at different control rod configurations. It was confirmed that the control rod movement affects the position of the maximum in the axial fission rate distribution, as well as the height of the local maxima. The optimal detector position, in which the redistributions would have minimum effect on its signal, was determined.
\end{abstract}

\section{Introduction}

The use of advanced Monte Carlo computational codes for reactor core calculations has increased significantly in the last decade, thus generating the need for experimental verification through the use of benchmark experiments. At the Jožef Stefan Institute (JSI) Reactor Physics Department a Monte Carlo model of the TRIGA Mark II reactor has been created in MCNP - Monte Carlo N-Particle Transport
Code (MCNP) [1]. The model was mainly used for criticality calculations, but was later upgraded and used also for calculation of other physical parameters of the core [2], [3], [4], such as the beta-effective and power distribution. Lately it has been thoroughly used for the computational support of experimental campaigns and for safety assessments of reactor experiments and modifications. The model has already been verified against experimental data for kinetic parameters and $\mathrm{Au}(\mathrm{n}, \gamma)$ and $\mathrm{Al}(\mathrm{n}, \alpha)$ reaction rates in the reactor irradiation facilities [5], [6]. From 2011 a series of experiments was performed in collaboration with Commisariat à l'énergie atomique et aux énergies alternatives (CEA), in order to experimentally verify calculated fission ( $U-235$ and $\mathrm{U}-238$ ) rate profiles in the core between the fuel elements by using miniature fission chambers.

The benchmark experiments performed at the JSI TRIGA Mark II reactor were aimed at measuring in-core fission rate distributions. Specially designed miniature fission chambers developed by the CEA were used [7]. The fission chambers were inserted into the core of the TRIGA reactor using guide tubes, which enabled the measurement of axial fission rate profiles at multiple radial positions. A Monte Carlo computational model of the reactor and the experiment configuration was constructed, which was used to calculate the reaction rate distribution inside the core of the reactor and to evaluate the experimental and computational uncertainties together with major benchmark biases. Major uncertainty sources like fuel composition, axial and radial positions of the fission chambers, core temperature effects and control rod position were investigated an additional analyses of the effect of fuel burn-up and computational model geometric biases were performed. A comparison of the measured and calculated fission rate profiles was made and a relatively good agreement between the two sets of data was found, with average relative discrepancies being within one sigma standard uncertainty. In small research reactors such as the JSI TRIGA, the neutron flux profile inside the reactor core changes significantly in the axial and radial direction. Moreover, the effect of the neutron flux redistribution due to the control rod movements is significant. Until now the reactor ex-core power monitoring 
system has been used, which is highly sensitive to the effects mentioned above. Therefore a new on line in-core system has been devised which would utilize multiple miniature detectors distributed throughout the core to average out the dependence of the signal on the detector and control rod position [8].

The evaluation results can serve the purpose of testing and verifying the innovative design of the absolutely calibrated miniature fission chambers, as well as help validate the values of basic reactor parameters. These are needed for the normalization of Monte Carlo neutron transport calculation results [9]. The high value of the absolute reaction rate benchmark was recognized with the inclusion of the experiment into the International Reactor Physics Experiment Evaluation Project Handbook (IRPhEP) [10].

\section{Experiment description}

The experiment was performed at the JSI TRIGA Mark II reactor, which is a pool type light-water reactor, with a maximum steady state power of $250 \mathrm{~kW}$. The core is submerged into a $6.25 \mathrm{~m}$ high and $2 \mathrm{~m}$ wide aluminum tank filled with water and has an annular configuration, consisting of six concentric rings, where cylindrical fuel rods clad with stainless steel are positioned. The fuel material is a homogeneous mixture of $88 \mathrm{wt} \% \mathrm{ZrH}$ and $12 \mathrm{wt} \%$ of $20 \%$ enriched uranium. The core itself is composed of two $1.9 \mathrm{~cm}$ thick aluminum supporting grids in which holes of different diameters are drilled. These serve the purpose of positioning the fuel elements, control rods and additional nuclear instrumentation. In total there are 91 locations for fuel elements and additional 26 smaller holes, 9 of which were used for the insertion of the fission chambers. The reactivity in the reactor is controlled by four individually operated control rods labelled the safety (S), transient (T), compensating $(\mathrm{C})$ and regulating $(\mathrm{R})$ control rod. The core is surrounded by a circular graphite reflector which contains a rotary specimen rack, as can be seen in Figure 1. Five excore detectors are positioned on the outside of the graphite reflector, which consist of neutron and gamma detectors used for measuring the reactor thermal power. Each of the five channels has an individual power measuring interval based on the sensitivity of the detector. At steady-state reactor operation the power is generally determined with the linear channel. The nuclear detectors are periodically calibrated with the calorimetric calibration method using electrical heaters [11] with $2 \%$ uncertainty.

Fission rate distributions in the core of the TRIGA reactor were measured in the experiment, therefore the type of the detector was chosen on the basis of several operational constraints and expected neutron flux. The detector used was a watertight miniature fission chamber (FC) connected to an integrated mineral cable, which was designed, manufactured and absolutely calibrated by CEA [7]. The detectors structure material was made of stainless steel, while the fission chambers were filled with a gaseous mixture of argon and nitrogen. They displayed a cylindrical shape with a $3 \mathrm{~mm}$ diameter. In the experiment two different fission chambers
(T) transient control rod $\bigcirc$ fuel element

(S) security c. r. co central channel

C) compensating c.r. PS) pneumatic system

(R) regulating c.r. IC irradiation channel
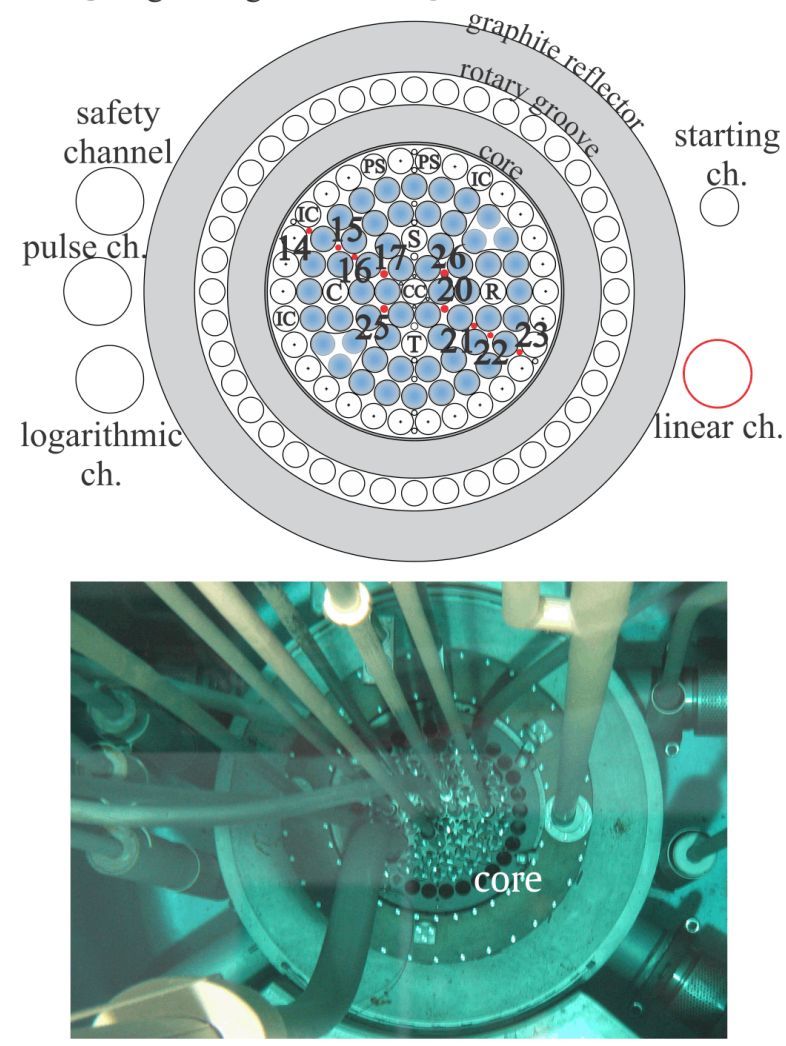

Figure 1. Top view of the reactor core, graphite reflector and ex-core nuclear detectors, with denoted measuring positions used for fission chamber insertion.

were used, which differed in the type and amount of fissionable material deposited on the walls of the active part - one with a fissionable coating composed mainly of ${ }^{235} \mathrm{U}$ (98.490\% at.) and the other of ${ }^{238} \mathrm{U}(98.964 \%$ at.) [12]. The fission chambers were operate in pulse mode at low fission rates, i.e. when individual pulses can be separated. The measurements presented in the article have been performed at relatively low neutron flux, i.e. $10^{10}$ neutrons $\mathrm{cm}^{-2} \mathrm{~s}^{-1}$ to $10^{11}$ neutrons $\mathrm{cm}^{-2} \mathrm{~s}^{-1}$ (reactor power $\sim 1 \mathrm{~kW}$ ). Initial measurements have been made to ensure a linear response of the fission chambers, the stability of the signal at steady state reactor power and to define the reactor power at which axial profiles would be recorded. It has been found that the optimal power was approximately $100 \mathrm{~W}$ for the ${ }^{235} \mathrm{U}$ fission chamber and $1000 \mathrm{~W}$ for the ${ }^{238} \mathrm{U}$ fission chamber. Measurements of fission rates were performed along the complete core height at 9 radial measurement positions, namely MP14, MP15, MP16, MP17, MP20, MP21, MP22, MP23, MP25 and MP26 denoted in Figure 1. FCs were deployed into the reactor core using a specially designed positioning system, comprising several hollow $\mathrm{Al}$ guide tubes, a drive mechanism and a data acquisition system. 
An integrated cable connecting the chambers and the data acquisition system was used for inserting and withdrawing the FCs into and out of the reactor core. The FC position was regulated by a pneumatic drive consisting of a series of valves and pistons. The axial positioning was ensured by an incremental system which measures the FC position relative to the reference position at the end of the guide tube and a linear system for absolute position measurements through the use of a magnetized strip. Fission reaction rates were measured at 24 axial locations inside the core with increment steps of approximately $25 \mathrm{~mm}$. A photograph of the positioning system is shown in Figure 2. The fission chamber positioning system was fixed on a horizontal support rod above the reactor pool with the stationed pneumatic system control panel providing the necessary pneumatic feed.

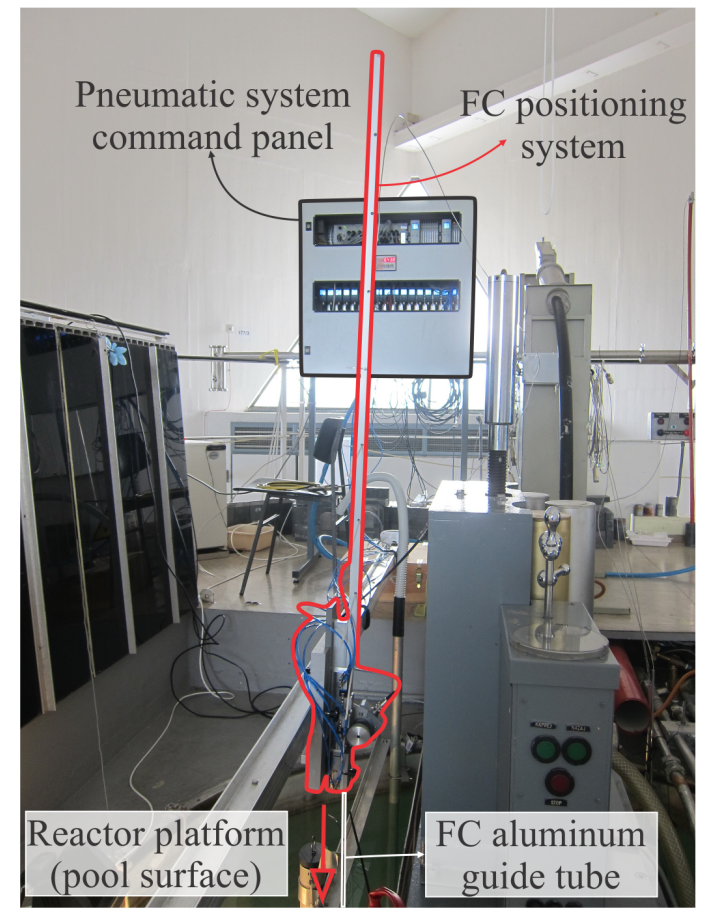

Figure 2. Photograph of the FC positioning system instalment above the pool of the TRIGA reactor.

\section{TRIGA Monte Carlo computational model}

The fission chamber experiment was modelled and inserted in the existing Monte Carlo model of TRIGA Mark II reactor [4], which has been validated against measurements in the past [6], [13]. The calculations were performed using the state-of-the-art Monte Carlo transport code MCNP version 6.1 [1] and ENDF/B VII.1 nuclear data library [14]. The fission reaction rates were calculated and averaged over the $4 \mathrm{~mm}$ high sensitive area of the fission chambers in 1 $\mathrm{mm}$ increments over the whole height of the reactor core. For measurement to calculation comparison the computation results had to be converted to absolute reaction rate units, i. e. counts per second. This was carried out using a normalisation factor $K[9]$ :

$$
R=K \cdot R_{m c} ; K=\frac{P \bar{\nu}}{w_{f} k_{e f f}},
$$

where $R$ is the absolute reaction rate, $R_{m c}$ is the Monte Carlo calculated reaction rate, $P$ is the reactor thermal power, $\bar{\nu}$ is the average number on neutron released per fission, $w_{f}$ is the average deposited energy per fission event and $k_{\text {eff }}$ is the calculated effective multiplication factor of the TRIGA computational model. The values of $\bar{\nu}$ and $w_{f}$ are constant in general and have values of $\bar{\nu}=2.439$ and $w_{f}$ $=193.7 \mathrm{MeV} \pm 0.1 \mathrm{MeV}$ [15]. Values of the calculated effective multiplication factor of approximately 1.0475 were higher than those of a critical system because fuel burnup was not taken into account in the reactor model. The schematic top and side views of the TRIGA benchmark model can be seen in Figure 3.

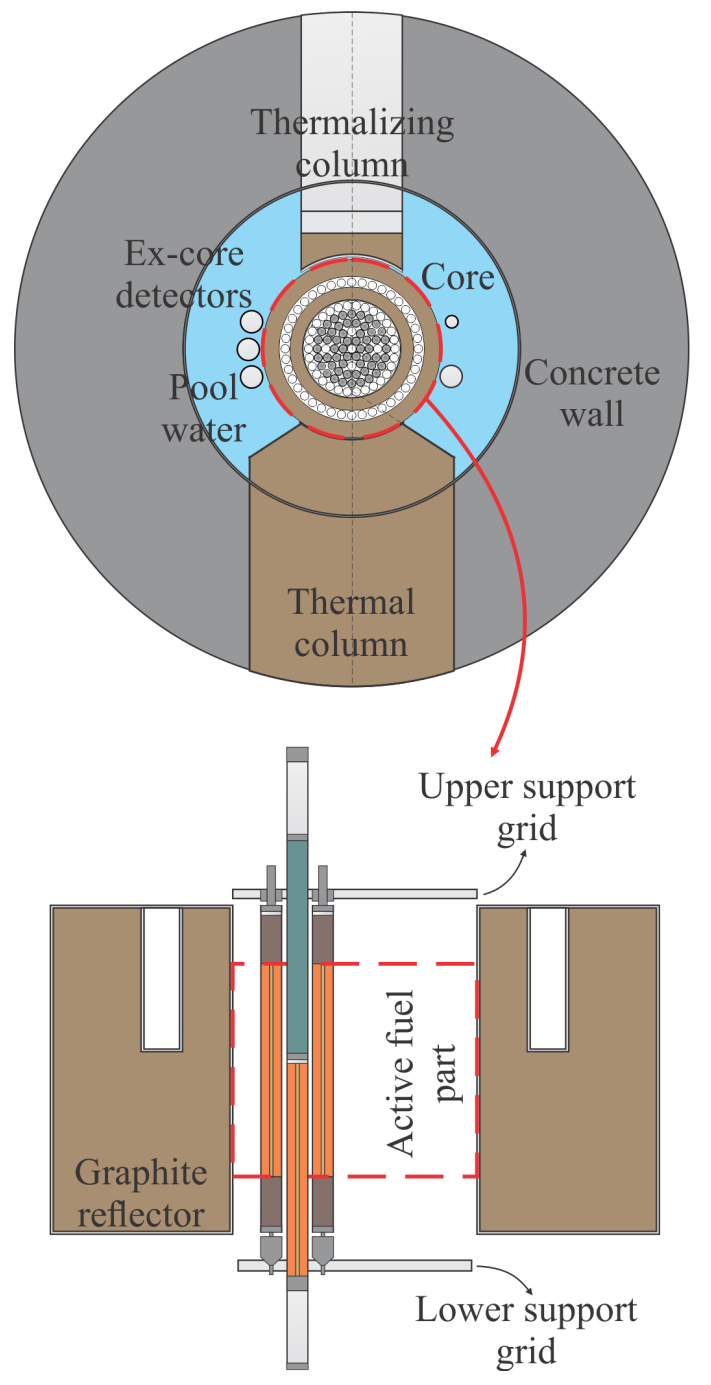

Figure 3. Schematic top and side views of the TRIGA reactor benchmark model. The reactor core within the water filled pool and the surrounding concrete shield are shown in the left-hand side. A close-up of the core is shown in the right-hand side with denoted fuel elements, control rods, support grids and graphite reflector. 


\section{Fission rate axial profiles}

The measured fission rate profiles and the ones calculated with the TRIGA Monte Carlo computational model were compared [8], [10]. The reference point (relative 0) of the fission chambers axial position was set to coincide with the top of the upper support grid and increasing towards the bottom of the reactor core. A comparison of absolute and relative (normalized to reaction rate maximum) fission rate profiles is shown for the ${ }^{235} \mathrm{U}$ fission chamber at measuring position MP20. One can see a relatively good agreement with the discrepancies being smallest at the active part of the core. The average relative differences in this area reach a value of less than $5 \%$.

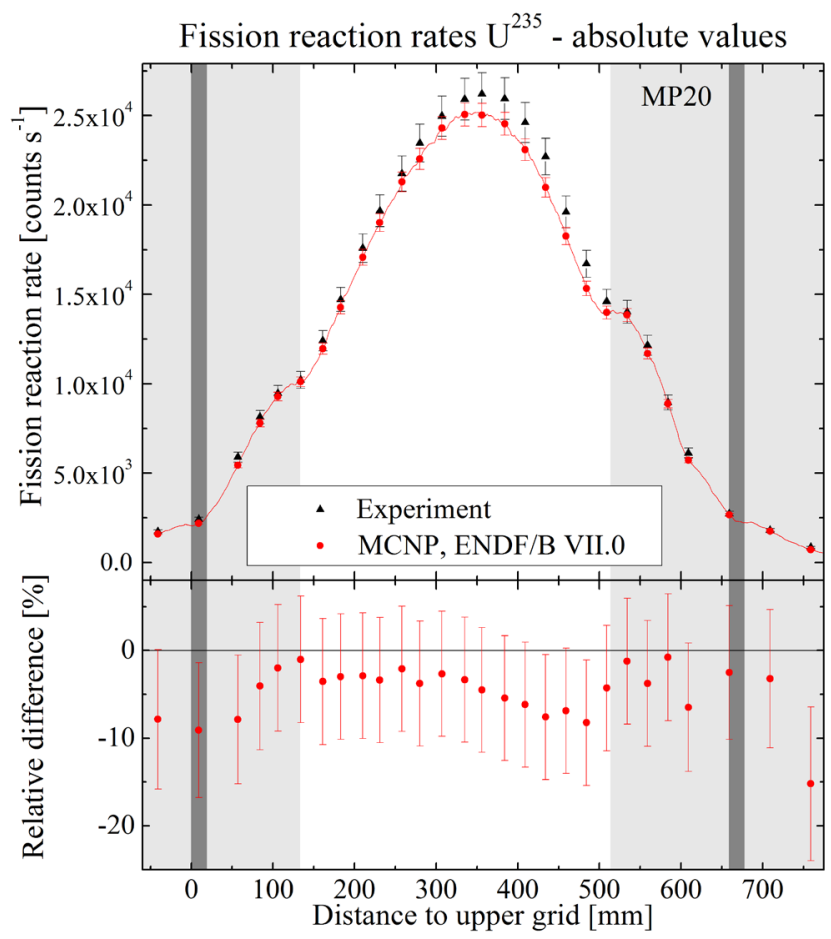

Figure 4. Comparison and relative discrepancies between the measured absolute fission rates and the ones computed with the Monte Carlo method for measuring position MP 20 - positioned near the centre of the core.

\section{Effect of control rod movement on the fission rate axial profiles}

In small research reactors such as TRIGA, the neutron flux and fission rate inside the reactor core can change significantly in the axial and radial direction [8], [10], [16], [17], [18]. The major effect of the neutron flux redistribution is due to the control rod movement. The neutron flux redistributions affects the power readings of current excore power monitoring system [11]. Using multiple in-core detectors gives a possibility to average out the dependence of the detector signal on the control rod position [19].

Experiments presented in this section were performed with multiple CEA manufactured miniature FCs, containing

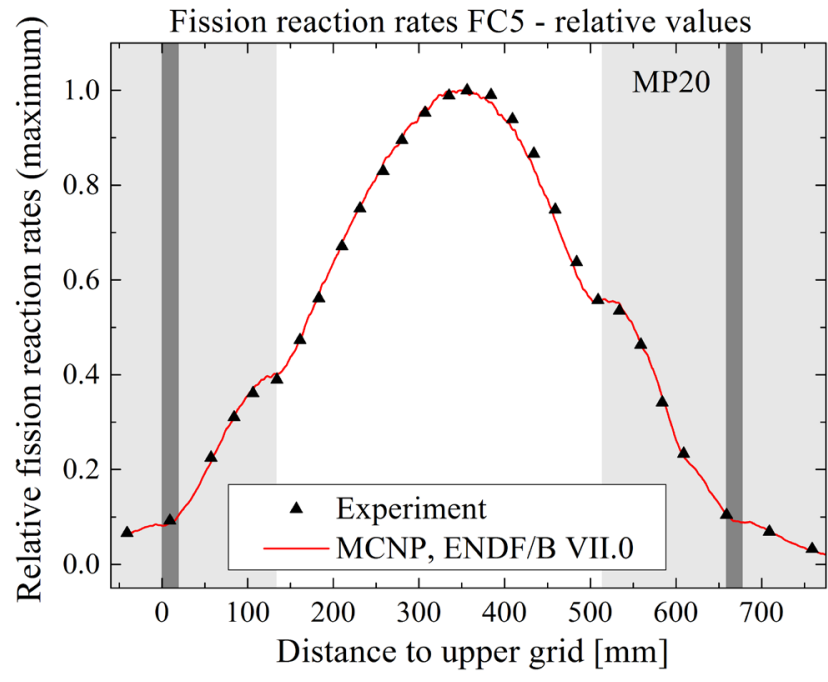

Figure 5. Comparison between the measured relative fission rates and the ones computed with the Monte Carlo method for measuring position MP 20.

$10 \mu \mathrm{g}$ of $97.663 \%$ enriched ${ }^{235} \mathrm{U}$, positioned in MP20, MP26, MP25 and MP17, which are denoted in Figure 1. Those measuring positions were chosen due to their symmetric position inside the reactor core and the symmetric position in regard to the regulating and compensating control rods. For performing and analysing the measurements the CEA design MONACO (Multichannel Online Neutron Acquisition Campbell mOde) system [20] was used. All FCs were operating in pulse mode and were positioned inside aluminium guide tubes, which enabled vertical movement through the reactor core. Positions of miniature FCs were changed manually in $5 \mathrm{~cm}$ steps. The schematic view of fuel and control rods configuration inside the reactor core is presented in Figure 6, where on top in grey is the upper grid, where reference point for measurements and calculations was chosen. Due to the reference position above the reactor core all other axial positions have a negative sign in Figure 6 . It should be noted that reactor was critical during the measurement with constant reactor power $100 \mathrm{~W}$, therefore when the regulating control rod was withdrawn, the reactivity was compensated by insertion of the compensating control rod. The regulating and compensating control rods consist of two parts: upper part contains strong neutron absorber $\mathrm{B}_{4} \mathrm{C}$, while the bottom part contains fuel.

Fission rate axial profiles were measured in above mentioned measuring positions at different control rod configurations. Fission rate axial profiles were normalized to the surface area below the graph, which enabled comparison of their shapes. The reported calculation uncertainties are $1 \sigma$ statistical uncertainties originating from Monte Carlo method. Relative calculation uncertainty was lower than $1 \%$. The reported $1 \sigma$ experimental uncertainties were obtained taking into account the uncertainty due to a number of counts measured, deviations in the reactor power during measurement, uncertainty in FC design and MONACO 


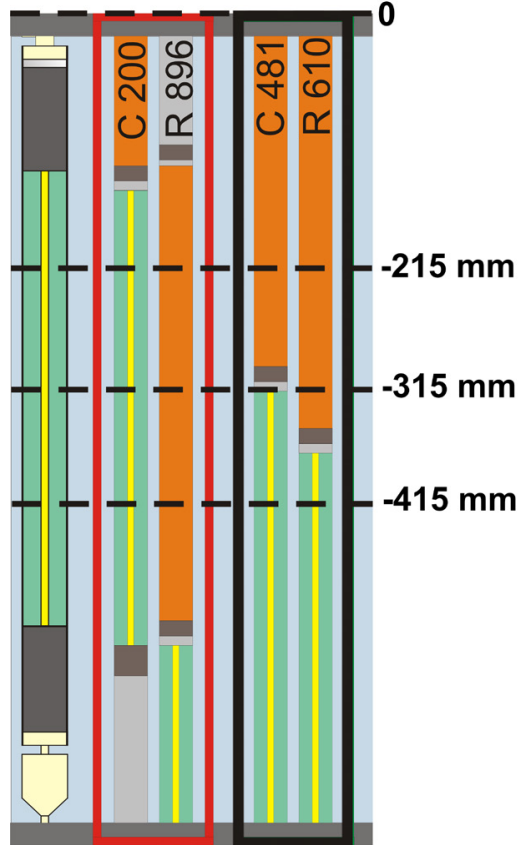

Figure 6. Schematic view of fuel and two control rods configuration inside the reactor core with a chosen reference scale. On each control rod its position is denoted in steps.

system. The total experimental uncertainty was obtained for individual FC and for individual measurement and was calculated to be $\sim 3 \%$. The major contribution to the experimental uncertainty is due to the uncertainty in the mass of the fissile deposit.

In Figure 7 measured and calculated fission rate axial profiles in MP20 at two different control rod configurations are presented. Difference between both axial profiles can be observed. Similar difference in axial profiles would also be observed if other measuring positions would be evaluated. The configuration of the evaluated control rod positions can be observed in Figure 6. In case of completely inserted regulating control rod (red configuration) inside the active fuel region is only absorber part of the regulating control rod in this case compensating control rod is completely withdrawn with only fuel follower within active fuel region. In this configuration the neutron flux distribution inside the core is more homogeneous in the axial direction and therefore the maximum of the axial profile is approximately in the middle of the active fuel height (red dashed line in Figure 7). When both control rods are only partially withdrawn (black configuration) the fuel follower of both control rods is in the lower part of the reactor core and absorber is inside the top part, which leads to more fissions in the lower part of the reactor core and maximum in the fission rate axial profile shifts to lower axial position as can be observed in Figure 7. Another deviation between both profiles that can be observed are also heights of the local maxima, which are consequence of the graphite inserts inside the fuel rod, which act as neutron reflector. In case of completely inserted regulating control rod (red configuration) both local maxima have approximately the same height, this is consequence of homogeneously distributed fission rate in axial direction. When both control rods are only partially withdrawn (black configuration), local maximum in the lower part is higher, because there is fuel part of the control rod and the top local maximum is lower, because there is neutron absorber.

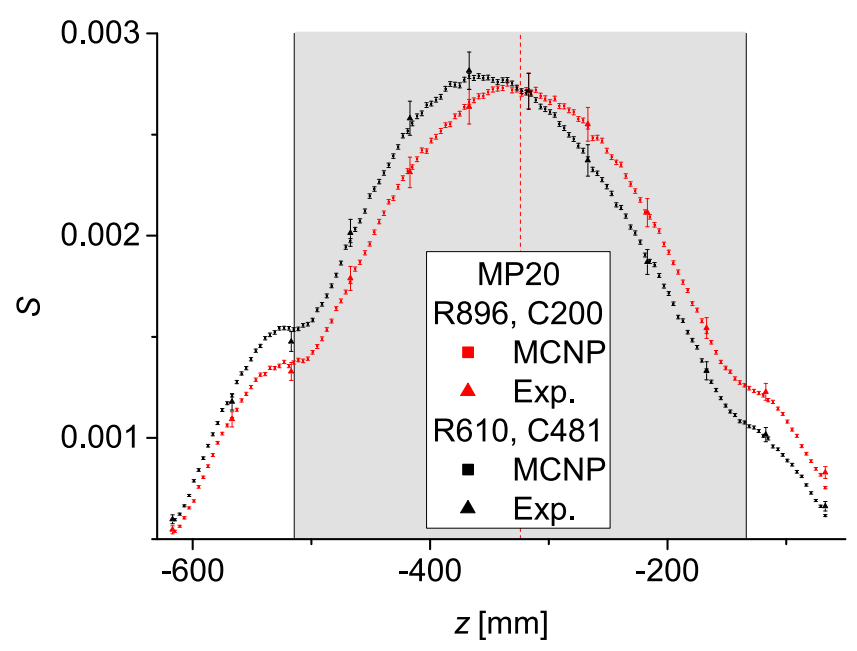

Figure 7. Comparison of fission rate axial profiles for MCNP calculations (squares) and experiment (triangles) at two different control rod positions. Red colour represents regulating control rod at step 896 and black colour regulating control rod at step 610. All distributions are normalized to the surface area below the graph. Error bars represent $1 \sigma$ statistical and measurement uncertainties. Area marked in grey represents the active fuel region and red dashed line represents middle of the active fuel height.

\section{Determination of optimal detector position}

After successful validation of computational model the fission rate has been calculated throughout the entire reactor core at different control rod configurations [18]. Redistributions due to the control rod movement were studied by observing $\chi^{2}$ distribution over the core. For evaluating the optimal detector position the $\chi^{2}$ with respect to the different control rod positions as function of detector position has been calculated using the expression:

$\chi^{2}\left(x_{i}, y_{j}, z_{k}\right)=\sum_{m}\left(\frac{N_{0, i, j, k}-N\left(x_{i}, y_{j}, z_{k}, m\right)}{\sigma_{m}}\right)^{2}$,

where the sum is performed over different control rod configurations. $N$ is a function of 3 spatial coordinates and therefore $N\left(x_{i}, y_{j}, z_{k}, m\right)$ represents calculated ${ }^{235} \mathrm{U}$ fission rates in fixed position inside the reactor core at $m^{\text {th }}$ control rod configuration and $\sigma_{m}$ represents statistical uncertainty of the individual $N\left(x_{i}, y_{j}, z_{k}, m\right) . N_{0, i, j, k}$ stands for average value of the calculated ${ }^{235} \mathrm{U}$ fission rates at fixed position and over the different control rod positions. Calculated $\chi^{2}$ distribution of fission rate in two different plane views is presented in Figure 8. The $\chi^{2}$ represents the deviations from the average value. In desired detector position $\left(x_{i}, y_{j}, z_{k}\right)$ the deviations from the average detector signal due to the 
control rod movement should be minimal and therefore the calculated $\chi^{2}\left(x_{i}, y_{j}, z_{k}\right)$ should be minimized. It can be observed that the largest deviations are around control rods and other positions inside the reactor core have much lower variations. It can be concluded that the best option for positioning neutron detector would be on the reactor core central line, symmetrically to the regulating and compensating control rod and approximately in the middle of the active fuel height.

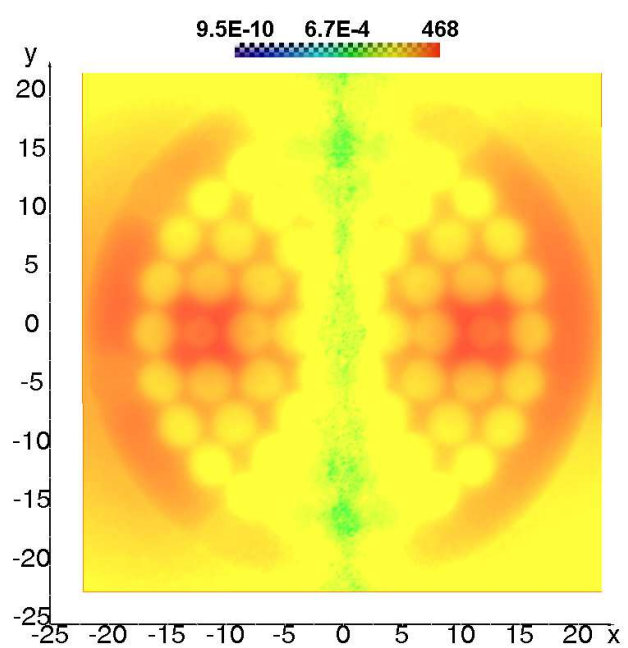

(a) xy plane

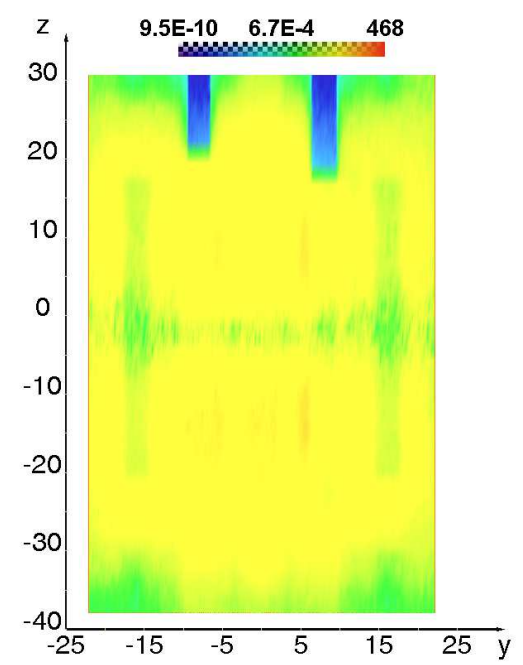

(b) yz plane

Figure 8. $\chi^{2}$ distribution in different planes, approximately in the middle of the reactor core. Values of $\chi^{2}$ are represented in colours ranging from low values in purple (dark) to high values in yellow (light).

\section{Evaluation of experimental and computa- tional uncertainty}

The comparison between the measured profiles of absolute reaction rates and those computed by Monte Carlo method displays a relatively good agreement. The fission rate values match within $1 \sigma$ standard uncertainty at most measuring positions and for both fission chambers, which implies on a sufficient accuracy of the computational model of the TRIGA Mark II reactor. To complete the validation an evaluation of the measurement and calculational uncertainties was performed. The combined experimental and computational uncertainty assessment are presented in Table 1 and Table 2. Several major biases were also studied - this included the core temperature effect because of using cross section data at room temperature in the reference computational model of the TRIGA reactor. The latter was found to have a negligible effect on the fission rate computations due to the low thermal power of the reactor at which the measurements were performed. The largest identified bias was the fuel burnup. Namely the reference model used fresh fuel, which at a relatively low TRIGA fuel burnup ranging from $0.7 \mathrm{MWd}$ to $4.8 \mathrm{MWd}$, introduced a fission rate bias of up to $3.5 \%$.

TABLE 1. AVERAGE EXPERIMENTAL RELATIVE STANDARD UNCERTAINTY OF THE FISSION CHAMBER RESPONSE.

\begin{tabular}{|l|l|}
\hline $\begin{array}{l}\text { Experimental uncertainty } \\
\text { source }\end{array}$ & $\begin{array}{l}\text { Average FC response } \\
\text { uncertainty [\%] }\end{array}$ \\
\hline \hline FC calibration & \pm 3.2 \\
\hline Fuel composition & \pm 1.4 \\
\hline${ }^{234}$ U and ${ }^{236} \mathrm{U}$ impurities & \pm 1.4 \\
\hline Hf impurities & \pm 1.3 \\
\hline FC axial position & \pm 2.6 \\
\hline FC radial position & \pm 0.5 \\
\hline Control rod position & \pm 0.3 \\
\hline \hline Combined uncertainty & \pm 4.8 \\
\hline
\end{tabular}

TABLE 2. AVERAGE COMPUTATIONAL RELATIVE STANDARD UNCERTAINTY OF THE FISSION CHAMBER RESPONSE.

\begin{tabular}{|l|l|}
\hline $\begin{array}{l}\text { Computational } \\
\text { uncertainty source }\end{array}$ & $\begin{array}{l}\text { Average FC response } \\
\text { uncertainty [\%] }\end{array}$ \\
\hline \hline Normalization factor $K$ & \pm 2.2 \\
\hline Nuclear data libraries & \pm 1.5 \\
\hline MC statistical uncertainty & From \pm 0.4 to \pm 3 \\
\hline \hline Combined uncertainty & From \pm 2.7 to \pm 4.0 \\
\hline
\end{tabular}

\section{Conclusion}

The presented paper focused on the various reaction rate benchmark experiments that were performed using CEA developed miniature fission chambers at the TRIGA Mark II research reactor, which operates at the Jožef Stefan Institute in Slovenia. In support of the measurements a detailed Monte Carlo calculational model of the TRIGA reactor was developed, upgraded and extensively validated against experimental data. The experiments presented in the paper based on recording axial scans of fission reaction rates at multiple measuring positions in the reactor core. A complete model verification and estimation of different uncertainty sources was performed, which enabled an assessment of the combined experimental and calculational reaction rate uncertainty. The comparison between the experimentally and 
computationally gained data showed good agreement for both fission chamber types with the average discrepancies in the active fuel part being below $5 \%$. In addition the redistribution of the axial profile due to the control rod movement was also studied. It was observed that the position of control rods can affect the position of maximum as well as the heights of the local maxima. To minimize the effect of control rod movement on the detector signal optimal detector position inside the reactor core was determined to be on the reactor core central line, symmetrically in regard to the regulating and compensating control rod and approximately in the middle of the active fuel height.

Because there are very few experiments that have been conducted on the basis of absolute fission rate measurements and supported by an extensive uncertainty assessment, the experiment evaluation was included into the International Reactor Physics Experiment Evaluation Project Handbook to further contribute to the research reactor community [10].

\section{References}

[1] J. T. Goorley, M. R. James, T. E. Booth, F. B. Brown, J. S. Bull, L. J. Cox, J. W. Durkee, J. S. Elson, M. L. Fensin, R. A. Forster, J. S. Hendricks, H. G. Hughes, R. C. Johns, B. C. Kiedrowski, R. L. Martz, S. G. Mashnik, G. W. McKinney, D. B. Pelowitz, R. E. Prael, J. E. Sweezy, L. S. Waters, T. Wilcox, and A. J. Zukaitis, Initial MCNP6 Release Overview - MCNP6 Version 1.0, Los Alamos National Laboratory, 2014.

[2] L. Snoj and M. Ravnik, "Calculation of Power Density with MCNP in TRIGA Reactor," in Proceedings of the International Conference Nuclear Energy for New Europe 2006. Portorož, Slovenia, 18 - 21 September: Nuclear Society of Slovenia, 2006.

[3] L. Snoj, A. Kavčič, G. Žerovnik, and M. Ravnik, "Calculation of kinetic parameters for mixed TRIGA cores with Monte Carlo," Annals of Nuclear Energy, vol. 37, no. 2, pp. 223-229, feb 2010. [Online]. Available: http://linkinghub.elsevier.com/retrieve/pii/S0306454909003302

[4] L. Snoj, A. Trkov, R. Jaćimović, P. Rogan, G. Žerovnik, and M. Ravnik, "Analysis of neutron flux distribution for the validation of computational methods for the optimization of research reactor utilization," Applied Radiation and Isotopes, vol. 69, no. 1, pp. 136-141, jan 2011. [Online]. Available: http://linkinghub.elsevier.com/retrieve/pii/S0969804310003611

[5] R. Jeraj and M. Ravnik, "TRIGA Mark II Reactor: U(20)Zirconium Hydride Fuel Rods in Water with Graphite Reactor, IEU-COMP-THERM-003," in International Handbook of Evaluated Criticality Safety Benchmark Experiments. Paris, France: NEA/NSC/DOC(95)03, OECD NEA, 2010.

[6] V. Radulović, Ž. Štancar, L. Snoj, and A. Trkov, "Validation of absolute axial neutron flux distribution calculations with MCNP with $197 \mathrm{Au}(\mathrm{n}, \gamma) 198 \mathrm{Au}$ reaction rate distribution measurements at the JSI TRIGA Mark II reactor," Applied Radiation and Isotopes, vol. 84, pp. 57-65, 2014.

[7] L. Barbot, C. Domergue, S. Breaud, C. Destouches, J.-F. Villard, L. Snoj, Ž. Štancar, V. Radulović, and A. Trkov, "Neutron field characterization of irradiation locations applied to the slovenian TRIGA reactor," in 2013 3rd International Conference on Advancements in Nuclear Instrumentation, Measurement Methods and their Applications (ANIMMA). IEEE, 2013, pp. 1-5. [Online]. Available: http://ieeexplore.ieee.org/document/6727954/

[8] T. Kaiba, G. Žerovnik, A. Jazbec, Ž. Štancar, L. Barbot, D. Fourmentel, and L. Snoj, "Validation of neutron flux redistribution factors in JSI TRIGA reactor due to control rod movements," Applied Radiation and Isotopes, vol. 104, 2015.
[9] G. Žerovnik, M. Podvratnik, and L. Snoj, "On normalization of fluxes and reaction rates in MCNP criticality calculations," Annals of Nuclear Energy, vol. 63, pp. 126-128, jan 2014. [Online]. Available: http://linkinghub.elsevier.com/retrieve/pii/S0306454913004003

[10] Ž. Štancar, L. Snoj, and L. Barbot, "Reaction Rate Distribution Experiments at the Slovenian JSI TRIGA Mark II Research Reactor, TRIGA-FUND-RESR-002," in International Handbook of Evaluated Reactor Physics Benchmark Experiments. Paris: NEA/NSC/DOC(2006)1, OECD NEA, 2017.

[11] Ž. Štancar and L. Snoj, "An improved thermal power calibration method at the TRIGA Mark II research reactor," Manuscript submitted for publication, 2017.

[12] Ž. Štancar, L. Snoj, L. Barbot, C. Destouches, D. Fourmentel, and J.-F. Villard, "Computational validation of the fission rate distribution experimental benchmark at the JSI TRIGA Mark II research reactor using the Monte Carlo method," Manuscript submitted for publication, 2017.

[13] L. Snoj, A. Trkov, M. Ravnik, and G. Žerovnik, "Testing of cross section libraries on zirconium benchmarks," Annals of Nuclear Energy, vol. 42, pp. 71-79, apr 2012. [Online]. Available: http://linkinghub.elsevier.com/retrieve/pii/S030645491100452X

[14] M. Chadwick, M. Herman, P. Obložinský, M. Dunn, Y. Danon, A. Kahler, D. Smith, B. Pritychenko, G. Arbanas, R. Arcilla, R. Brewer, D. Brown, R. Capote, A. Carlson, Y. Cho, H. Derrien, K. Guber, G. Hale, S. Hoblit, S. Holloway, T. Johnson, T. Kawano, B. Kiedrowski, H. Kim, S. Kunieda, N. Larson, L. Leal, J. Lestone, R. Little, E. McCutchan, R. MacFarlane, M. MacInnes, C. Mattoon, R. McKnight, S. Mughabghab, G. Nobre, G. Palmiotti, A. Palumbo, M. Pigni, V. Pronyaev, R. Sayer, A. Sonzogni, N. Summers, P. Talou, I. Thompson, A. Trkov, R. Vogt, S. van der Marck, A. Wallner, M. White, D. Wiarda, and P. Young, "ENDF/B-VII.1 Nuclear Data for Science and Technology: Cross Sections, Covariances, Fission Product Yields and Decay Data," Nuclear Data Sheets, vol. 112, no. 12, pp. 2887-2996, dec 2011. [Online]. Available: http://linkinghub.elsevier.com/retrieve/pii/S009037521100113X

[15] Ž. Štancar, Computational analysis of power profile measurements in the TRIGA reactor (in Slovene). Master Thesis, 2014.

[16] Ž. Štancar, L. Snoj, and L. Barbot, "Evaluation of the Effect of BurnUp on Neutron Flux and Reaction Rate Distributions in the TRIGA Mark II Reactor," in Proceedings of the International Conference PHYSOR 2016 - Unifying Theory and Experiments in the 21st Century. Sun Valley, Idaho, USA, May 1-5 2016: American Nuclear Society, 2016, pp. 1950-1959.

[17] G. Žerovnik, T. Kaiba, V. Radulović, A. Jazbec, S. Rupnik, L. Barbot, D. Fourmentel, and L. Snoj, "Validation of the neutron and gamma fields in the JSI TRIGA reactor using in-core fission and ionization chambers," Applied Radiation and Isotopes, vol. 96, pp. 27-35, feb 2015. [Online]. Available: http://linkinghub.elsevier.com/retrieve/pii/S0969804314003819

[18] T. Kaiba, G. Žerovnik, L. Barbot, D. Fourmentel, C. Destouches, A. Jazbec, and L. Snoj, "Evaluation of neutron flux and fission rate distributions inside the JSI TRIGA Mark II reactor using multiple incore fission chambers," Manuscript submitted for publication, 2017.

[19] G. Žerovnik, L. Snoj, A. Trkov, L. Barbot, D. Fourmentel, and J.-F. Villard, "Measurements of Thermal Power at the TRIGA Mark II Reactor in Ljubljana Using Multiple Detectors," IEEE Transactions on Nuclear Science, vol. 61, no. 5, pp. 2527-2531, oct 2014. [Online]. Available: http://ieeexplore.ieee.org/lpdocs/epic03/wrapper.htm?arnumber=6906305

[20] M. Thevenin, L. Barbot, G. Corre, R. Woo, C. Destouches, and S. Normand, "Digital Real-Time Multiple Channel Multiple Mode Neutron Flux Estimation on FPGA-based Device," EPJ Web of Conferences, vol. 106, p. 05009, feb 2016. [Online]. Available: http://www.epj-conferences.org/10.1051/epjconf/201610605009 